\title{
3D Digital Imagery a Solution for the Teaching of Osteology: Example of the Thoracic cage
}

Mar N B ${ }^{1}$, Seye $\mathrm{Ch}^{2}$, Yacouba Garba K ${ }^{3}$, Niang I ${ }^{4}$, Seck I D ${ }^{3}$, Sahoun M4, Ba S ${ }^{4}$, Ndoye $\mathrm{JM}^{3}$, Ndiaye $\mathrm{A}^{3}$, Niang $\mathrm{E} \mathrm{H}^{5}$, Diop $A \mathrm{~N}^{6}$, Ndiaye $A s^{7}$.

*1 Anatomy laboratory, Iba Der THIAM University of Thiès.

${ }^{2}$ Anatomy laboratory, Alioune DIOP University of Bambey.

${ }^{3}$ Anatomy and Organogenesis Laboratory, FMPO, UCAD.

${ }^{4}$ Radiology Department of Fann Hospital.

${ }^{5}$ Radiology Department of Aristide Le Dantec Hospital of Dakar.

${ }^{6}$ Radiology Department of Gaston Berger University, Saint Louis, Sénégal.

${ }^{7}$ Anatomy laboratory, Assane SECK University of Ziguinchor.

\section{ABSTRACT}

Osteology is a fundamental discipline, its classical teaching becomes difficult because of plethora of students and shortage of bony parts. It's in this context that we have made, from 3D volume imaging, a modeling of the rib cage as a test using a software for post-treatment of CT images in order to propose a pedagogical tool for studying thorax's skeletal and adding descriptions with the help of classical works.

This was a prospective study involving 27 patients aged between 35 and 45 years. The scanners used were HITACHI ECLOS 16 cuts. Once the CT scan was selected, the DICOM data was transmitted to the post-processing console. The images were processed on the console "Aquarius Intuition Edition Version 4. 4. 7. 855113", for one patient we used Veiwer Osirix 10.6.8 Mac.

All bones have been dynamically described thanks to the volume rendering. We thus obtained volumetric reconstructions of three-dimensional CT images of the different bone structures superimposed on those taught in classical anatomy practical work. We obtained a scenario of practical work in the form of a slide show that the teacher can use for works with or without model and even remotely.

The virtual reality obtained with the 3D reconstructions of CT scans of the rib cage is a tool for self-learning of osteology for students but also a way for teachers to do practical work without having to use models, and even at a distance.

KEY WORDS: 3D imaging, Teaching, Tomodensitometry, Osteology.

Corresponding Author: Dr. Ndeye Bigue MAR, Anatomy laboratory, Iba Der THIAM University of Thiès. E-Mail: biguemarmbaye@yahoo.fr

Access this Article online

Quick Response code

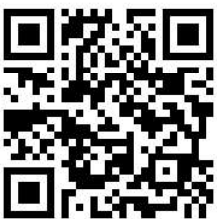

DOI: $10.16965 /$ ijar.2021.169

Journal Information

\section{International Journal of Anatomy and Research}

ISSN (E) 2321-4287 | ISSN (P) 2321-8967

https://www.ijmhr.org/ijar.htm

DOI-Prefix: https://dx.doi.org/10.16965/ijar

\section{Article Information}

Received: 12 Sep 2021

Peer Review: 13 Sep 2021

Revised: 30 Sep 2021
Accepted: 05 Oct 2021

Published (O): 05 Dec 2021

Published (P): 05 Dec 2021

\section{INTRODUCTION}

Osteology is a fundamental discipline in the teaching of anatomy [1-4]. It is one of the subjects whose learning requires direct contact between learners and trainers based on demonstration from bone parts from corpses or models [5]. However, its teaching poses problems related to the variation in the number of bone parts (deterioration and/or loss) and the increasingly excessive number of 
Mar N B, Seye Ch, et al., 3D Digital Imagery a Solution for the Teaching of Osteology: Example of the Thoracic cage.

students. The rise of $3 D$ imaging has given renewed interest to the contribution of 3D modelling in the teaching of osteology [4].

Evidence from the literature suggests that osteology is one of the medical disciplines likely to benefit from 3D technology that has improved diagnostic and prognosis learning methods [4]. Indeed, 3D technology serves as the basis for quantitative morphometry, a major tool for diagnostic, prognostic and therapeutic evaluation. It is a beautiful educational tool that has already facilitated the understanding of vascular anatomy and its virtual dissections [6]. The use of volumic $3 \mathrm{D}$ reconstructions obtained with the scanner in the teaching of osteology could solve difficulties encountered by this discipline in our universities.

The objective of this work is to propose a volumetric 3D modeling of the chest cavity using software for post processing CT images and to establish an educational tool allowing the student to do practical work, alone or with the teacher. This will thus provide the latter and the learners with a tool that does not replace the traditional means of learning osteology but which would allow them to benefit from a new pedagogical approach that could lead to self-teaching.

\section{MATERIALS AND METHODS}

Material: The scanners used were 16-slice Hitachi ECLOS. The "Ulead Video Studio 11.0 Plus» and Veiwer Osirix 10.6.8 software were used respectively for video editing and generation of educational scenarios in static VRT (Three-dimensional Volume Rendering) with dynamic annotation and VRT without annotation.

The population consisted of 27 patients including 19 men and 8 women to select the best specimen. Patients ranged in age from 35 to 45 years. This age range allowed us to have a good rendering while avoiding excessive ossifications or degenerative deformations. Patients were selected on the basis of inclusion and non-inclusion criteria:

Inclusion criterion: integrity of bone structure (no trauma, malformation or other lesions)
Non inclusion criterion: the existence of an anatomical variant interfering with the description.

\section{METHOD}

The work took place from 01 August 2015 to 30 October 2015 in the radiology department of National University Hospital of Fann.

This was a prospective study of the selection of human models for the study of thoracic osteology. This selection was made on a series of CT scans using millimetre volume acquisitions without and with contrast injection covering the chest cavity.

Once the CT exam was selected, the DICOM data was transmitted to the post-processing console. Thus at first we had modelled the thoracic cage to show the area at the depth: the skin, the muscles, its shape but especially its osseocartilaginous constitution which can reveal the organs of the mediastinum and the lungs on the thresholding. Then we had done the cutting with the "ROI» function on the «Aquarius Intuition Edition Version 4. 4. 7. 855113 " console. Each cut piece has been saved in the interface library. An instructional scenario was written and recorded based on a classic presentation of an anatomy lesson "in practice" while specifying the type of view and the anatomical elements to be described.

We reproduced the same anatomical views according to the 3D model on the console and took as an objective to produce a 3D scene similar to what the student must see during the practical work (TP) of anatomy. In the interest of confidentiality, we removed the annotations, including the patient's identity. The video export setting has been set to $1024 * 1024$ pixels resolution and 25 frames per second.

A 3-second capture on the posterior view allowed the dorsal spine to be taken out with a progressive thresholding after having cut it, thus allowing the student to have a threedimensional idea of this view.

Forward, a capture on the sternum in $20 \mathrm{sec}-$ onds with progressive thresholding of the anterior view made it possible to see the cartilage thus connecting the ribs to the sternum but also to describe its different views. 
Mar N B, Seye Ch, et al., 3D Digital Imagery a Solution for the Teaching of Osteology: Example of the Thoracic cage.

Finally, laterally a 20-second capture showed the 12 pairs of ribs and then insisted on the characters of at least one of each of the three groups of ribs with different catches of 5 to 8 seconds.

For the first rib, we modeled the rib cage in 4 seconds and then captured it in 6 seconds to show its position. Finally, after cutting it out, the modeling allowed us to capture different views from 15 to 20 seconds. This allowed us to describe the medial, front, profile, top and bottom views with the miniature video as the orientation (Figure 1).

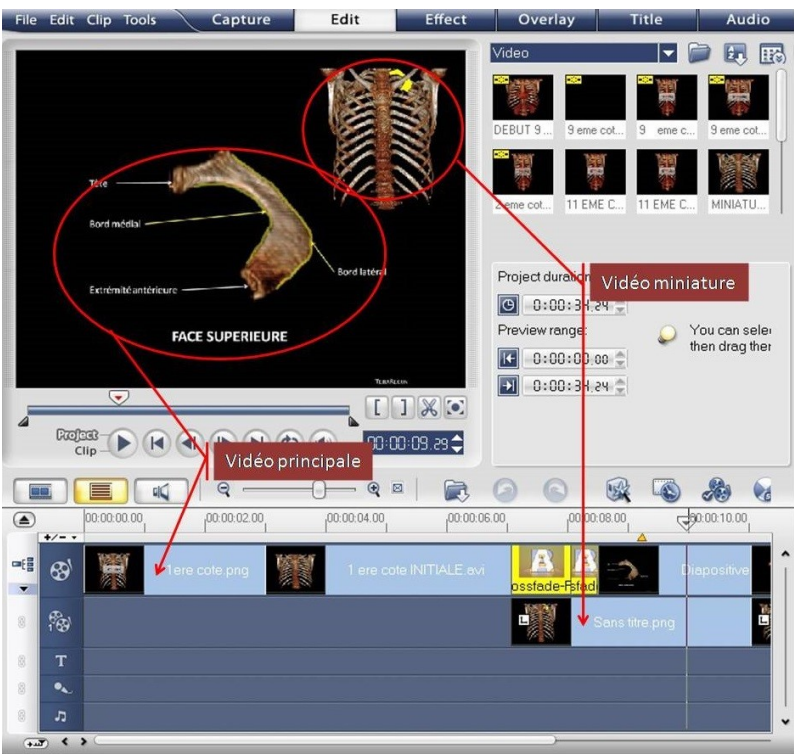

Fig. 1: Top and bottom views with the miniature video as the orientation.

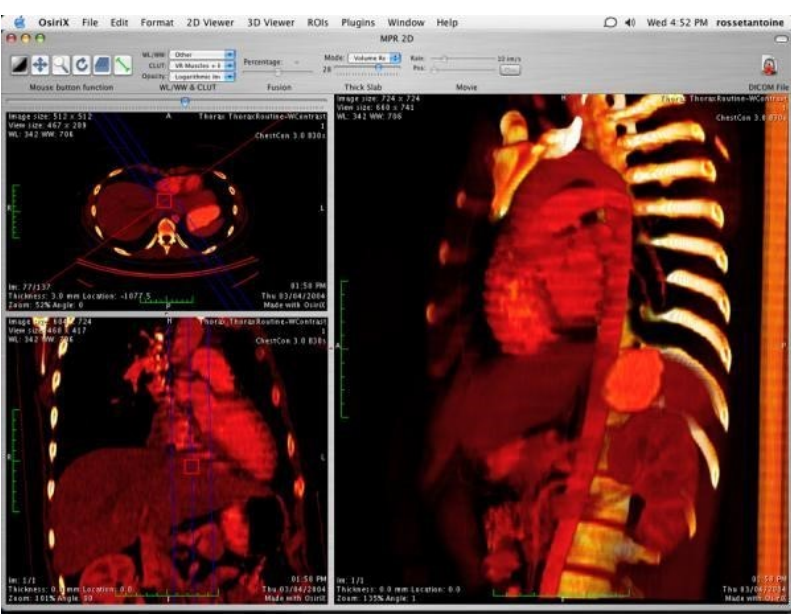

Fig. 2a: Different density thresholds were performed on the thoracic volume.

We also generated videos of the entire rib cage according to the scenarii for each piece. This was used for the miniature video on the upper right corner of the screen and would be used for orientation in space for the study of the coasts (Figure 1).
In one patient, we used the Veiwer Osirix 10.6.8 software with generation of static VRT educational scenarios with dynamic annotation and VRT without annotation. Different density thresholds were performed on the thoracic volume (Figure $2 \mathrm{a}$ ).

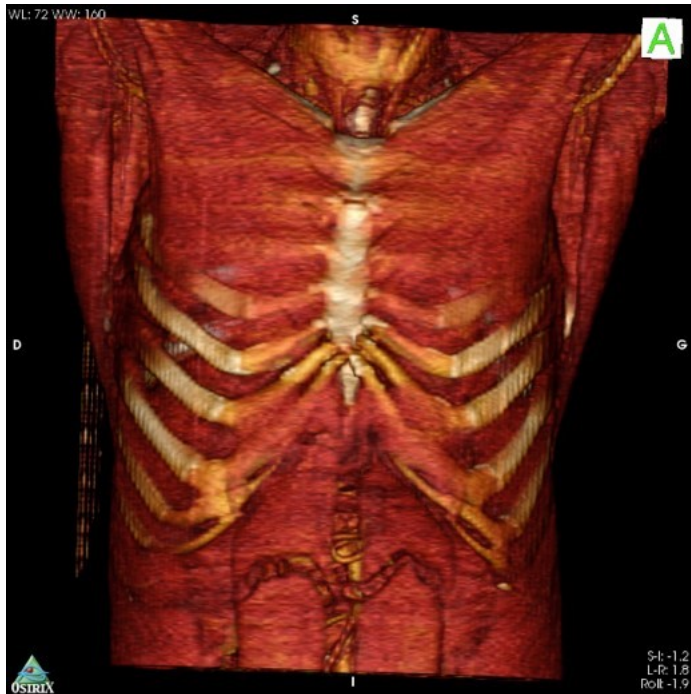

Fig. 2b: Thresholding and modeling of the muscles of the anterior chest wall and part of the rib cage.

\section{RESULTS}

The results were presented as a slideshow of Microsoft Power Point 1997-2003. Following the modeling we obtained 3D volumetric images superimposed on the film of the real bones available in the anatomy laboratories. Thus, for the sternum, the modeling allowed, a precise and animated description of its different parts especially the reliefs and muscle insertions that the student needs. The same applies to the twelve pairs of ribs. Concerning the coasts, we had described the first, the second, the eleventh and one from the third to the tenth because the latter have the same characters. It was the same for the dorsal hinge whose animation had made it possible to extract the vertebra type and to make the video of its description by insisting, by image stop on its constituents anterior arch and its different parts, posterior arch and its different parts (Figure $3 d$ ).

Long before that, we had first defined the thorax as the part of the trunk between the neck and the abdomen and shown from the area to the depth: 
- The container made of the skin (Figure 1); muscles (Figure $2 \mathrm{~b}$ ) and the osteococartilaginous envelope (Figure 2a) lined inside by the parietal pleura;

- The contents of the lungs, lined with the visceral pleura, and the organs of the mediastinum (figure 2a). Then the thoracic cavity which has an upper opening (formed forward by the jugular incision backward by the first thoracic vertebra and laterally the first ribs) less wide than its lower opening formed in front by the cartilages of the 7 th ribs, in back by the $12^{\text {th }}$ thoracic vertebra and the 12 th ribs, laterally by the lower edges of the last cartilages (figure 3c). Then modeling showed the following captures: forward the sternum (figures $3 a$ et $3 b$ ) and costal cartilages, backward the thoracic or dorsal vertebrae (figure $3 \mathrm{e}$ ) and the parts of the ribs behind the costal angles, and laterally by the convex middle segments of the first ten ribs (Figures 3c).

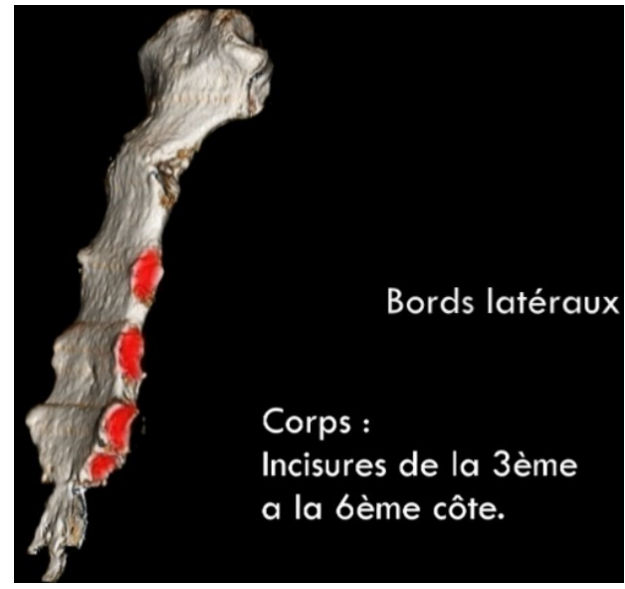

Fig. 3a: capture on a lateral edge of the sternum with its costal incisures.

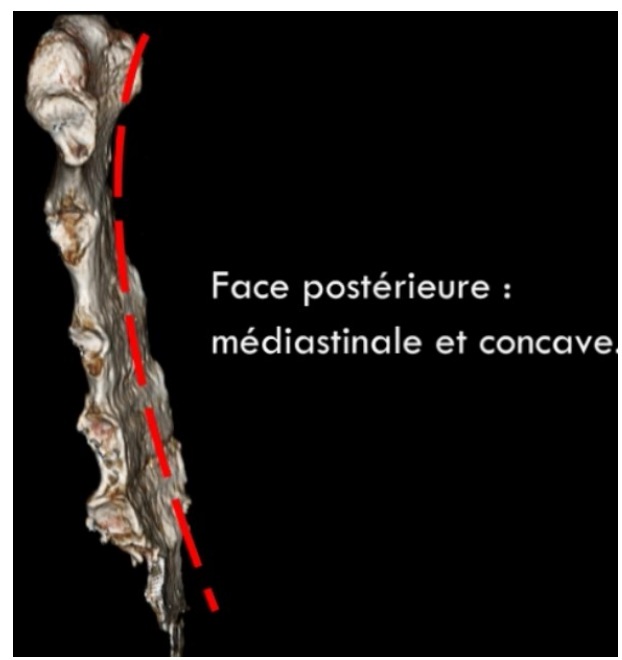

Fig. 3b: Capture showing the posterior surface of the sternum: highlighting its concavity.

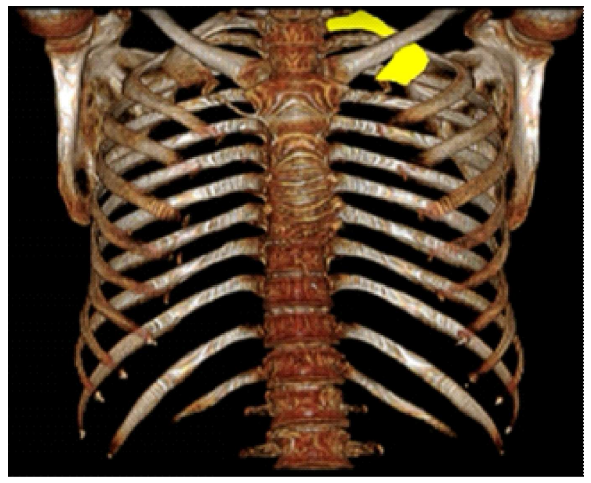

Fig. 3c: VRT reconstruction of the rib cage with placement of the first rib.

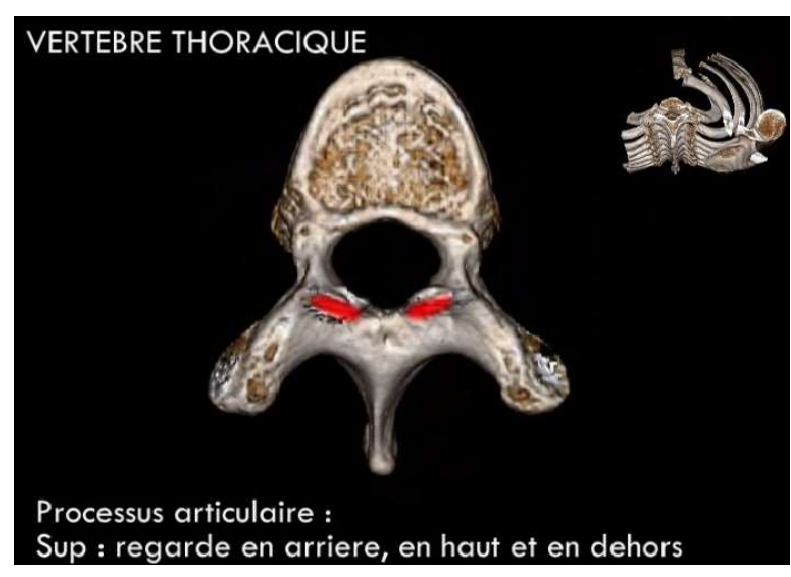

Fig. 3d: Superior view of the thoracic vertebra Top with the miniature video as the orientation.

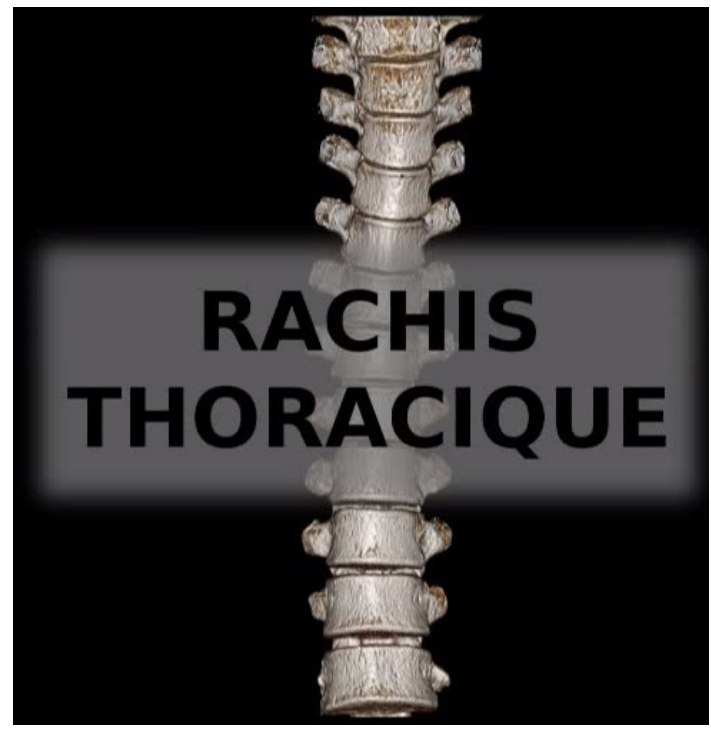

Fig. 3e: Modeling of the dorsal spine showing its 12 vertebrae, one of which is extracted and described from.

\section{DISCUSSION}

New technologies (computer and multimedia) have recently provided valuable tools for the study of human morphological sciences. In addition to the classical techniques of anatomical dissection, injections, or the study 
of anatomical sections combined with specific preparations or colorations, The use of virtual reality has opened up new fields of investigation through 3D modelling of anatomical structures. "Anatomical Virtual Reality" is the computer manipulation of realistic "3D objects" resulting from the modeling of anatomical structures [6-8].

The teaching model of osteology that we propose in this work, based on volumetric 3D reconstructions of scannographic images, has the benefit of enhancing interactivity. The realism of 3D reconstructions and the possibility of vision in relief make it an educational, attractive and evolutionary tool. Modeling can also be used to simulate anatomical systems such as the rib cage. These new methods can be an excellent complement to the classical teaching of anatomy and dissection that retain their place [6].

MAGIN et al. [9] in their work entitled "Realisation of a teleteaching tool: virtual anatomy of the skull of dogs" have produced a CD-ROM to have a good approach to the comparative anatomy of the skull of dogs. This study is similar to ours. We used the human rib cage as a complex set of bones, cartilages and joints. Its study by 2D diagrams is relatively difficult, in our opinion, for the student. The use of models, where they exist, is the only way of learning close to reality in our universities in Senegal.

Sahoun et al. [10] had shown in their work the interest in augmented reality in pelvic surgery through the same 3D reconstructions. Our work is inspired by the National Library of Medicine's "visible human" project in the USA [11] which has given rise to numerous works on anatomical sections with the aim of contouring and expert identification of the different structures in order to achieve segmentation. This made it possible to have a number of vectorial 3D modeling, whose applications are multiple, making this project the digital reference in anatomy [12]. The applications of this project have far surpassed the teaching of anatomy to extend to fields as diverse as art, industry and surgical simulation.

Uhl et al. [6] have already investigated virtual Int J Anat Res 2021, 9(4):8133-38. ISSN 2321-4287 dissection for vascular system study. This allowed them to enrich the classical techniques of study of anatomy (corrosion, dissection plastination) and to facilitate the understanding of vascular anatomy with dissections that no longer pose the problem of the acquisition of corpses, of their conservation, their number and study rooms (laboratories) for students. They posed the same problems as we did.

$3 \mathrm{D}$ reconstruction would be a tool that will pave the way for therapeutic simulation and assisted surgery. The student will be able to roll out his film, understand its objectives through volume rendering and use the audio recording as an add-on. Indeed the addition of an audio recording to our slideshow will result in the design of a CD of self-teaching.

Delingette et al [13] used manual segmentation based on automatic methods by providing a priori knowledge of segmented methods. This manual segmentation validated by a specialist had confirmed our study. Indeed, for the bones, this poses relatively no problem, they have a particular intensity in the image; the spongy bone of light intensity is surrounded by cortical bones of dark intensity. So the boundary between bone and muscle is well defined.

Gilles et al. [14] looked at the lower limbs (bones, muscles). They, like us, were confronted with the limited amount of data and literature available. However, encouraging results independent of anatomical structures and dependent on the perspectives envisaged by their study, could be found in the literature.

Pujol et al. [4] found that the regular evolution of educational tools and the development of multimedia methods could offer solutions to the problems faced by faculties. (increase in staff, demand for interactivity, responsiveness and online courses). Thus, they used 3D reconstructions to suggest self-teaching in response to organizational problems. However, this was in no way intended to alter the quality of the courses, nor to restrict the students' prior learning, nor to make it more difficult for the teachers to prepare the courses, but rather to solve the difficulties. This was the 
origin of all the success of their study which constitutes one of the perspectives of ours and strengthens us in our project. The design of interactive tasks using 3D models would provide students with the possibility to interactively manipulate the models. This would facilitate the construction of a graphical mental image of forms and relationships that may be more useful than 2D drawings.

Thus, in recent years 3D printing has been used in the design of 3D prototypes for teaching anatomy among others $[1,15-18]$.

\section{CONCLUSION}

Three-dimensional imaging could bring a plus to the teaching of osteology. This contribution determined by specific factors has been confirmed by several studies on CT scans and volume rendering involving many anatomical structures.

Our results showed that the teaching of osteology would benefit from using threedimensional reconstructions, which, in addition to being comparable to the classical method, are innovative and adapted to the current situations of our universities. They offer the benefits of accessibility to a greater number of students, of self-teaching even at a distance, and make it possible to overcome the organizational, financial and spatial constraints of a laboratory of anatomy.

This preliminary work must be completed by an extension to the whole skeleton in order to constitute an anatomical database for the teaching of human osteology. Future work could include generating 3D models of more complex structures, such as liver segments for use at a higher level. Likewise, it would be judicious to evaluate this teaching method by carrying out a comparative study in two groups of students (classical method VS method using 3D reconstructions) in Senegal's universities.

\section{Conflicts of Interests: None}

Authors' contributions: All authors contributed to the writing and proofreading of the manuscript

\section{REFERENCES}

[1]. Guyard A, Tamames L. Contrubution à une démarche de validation en bonnes pratiques biomédicales en établissement de santé : la grille de réponse [https:// www.utc.fr/ farges/dess_tbh/].

[2]. Leguerrier A. Nouveaux Dossiers d'AnatomieP.C.E.M.:Thorax. Heure de France, Paris, $2^{\text {ème }}$ édition 2005:19-24.

[3]. Delmas V. Anatomie générale. Elsevier Masson SAS, Paris, ,2008:262-263.

[4]. Pujol S, Baldwin M, Nassiri J, Kikinis R and Shaffer K. Using 3D modeling techniques to enhance teaching of difficult anatomical concepts. Radiologic education 2016, 23 (4):507-516.

[5]. Kamina P. Anatomie Clinique Tête Cou Dos. Maloine 3ème édition 2006 ;130-138.

[6]. Uhl J-F, Ordureau S, Delmas V. Les nouveaux outils de dissection virtuelle pour l'étude anatomique du système vasculaire. e-mémoires de l'Académie Nationale de Chirurgie, 2008;7(2):39-42.

[7]. Satava RM. Medical applications of virtual reality. J Medical Systems 1995;19(3):275-280.

[8]. Abouashem Y, Daya M, Savanah S, Strkalj G. The application of $3 d$ printing in anatomy education. Med Educ Online 2015;20:29847.

[9]. Majin M. Réalisation d'un outil de Télé-ensei-gnement: anatomie virtuelle du crâne de chiens. Thèse de médecine Vétérinaire. Toulouse 2005.89 pages.

[10].Sahnoun M. De la réalité augmentée pour l'apprentissage de la chirurgie pelvienne gynécologique. Thèse médecine université de SFAX année 2010.

[11]. Ackerman M J. The Visible Human project. A resource for education. Acad Med 1999;74:667-670.

[12]. Cotin S, Delingette H, Ayache N. Real time volumetric deformable models for surgery simulation. In Visualization in Biomedical Computing, Proceedings, volume 1131 of Lecture Notes in Computer Science. Springer Verlag Heidelberg-New York, September 1996.

[13]. Delingette H. General object reconstruction based on simplex meshes. International Journal of Computer Vision, Springer Verlag, 1999;32(2):111-146.

[14]. Gilles B, Moccozet L, and Magnenat-Thalmann N. Anatomical Modelling of the Musculoskeletal System from MRI.: MICCAI, 2006;LNCS 4190:289-296.

[15]. Negi S, Dhiman S, Kumar Sharma R. Basics and applications of rapid prototyping medical models. Rapid Prototyp J 2014;20(3):256-267.

[16]. Etchepareborde S F P. Contribution à la réalisation d'un CD-ROM le d'ostéologie comparée des mammifères domestiques.These médecine vétérinaire.- tou3$4070 ; 2005$.

[17]. Evrard Y, Mouchel J, Strainchamps D. Imagerie 3D en Tomodensitométrie. Master en Management des technologies en santé, Université de Technologie de Compiègne, 2005.

[18]. Rengier F, Mehndiratta A, Von Tengg-Kobligk H, Zechmann C M, Unterhinninghofen $\mathrm{R}$, Kauczor $\mathrm{HU}$ and Giesel F L. 3D printing based on imaging data : review of medical applications. Int J Comput Assist Radiol Surg 2010;5:335-341. 